\title{
Dopa responsive dystonia with Turner's syndrome: clinical, genetic, and neuropsychological studies in a family with a new mutation in the GTP-cyclohydrolase I gene
}

\author{
M Nitschke, D Steinberger, I Heberlein, V Otto, U Müller, P Vieregge
}

\begin{abstract}
A 26 year old woman with dopa responsive dystonia and cytogenetically confirmed Turner's syndrome had bilateral globus pallidus hypointensity on brain MRI. Among the living members of a five generation pedigree the patient's mother and the mother's sister also had dopa responsive dystonia; a maternal grandfather had senile parkinsonism, his niece isolated postural tremor. No other family member had Turner's syndrome. A new missense mutation in exon $I$ of the gene of GTP-cyclohydrolase I was found in the three family members with dopa responsive dystonia. With levodopa substitution the patients with dopa responsive dystonia improved clinically as well as in quantitative tests on hand tapping, verbal and performance IQ, concept formation, and set shifting abilities.

(F Neurol Neurosurg Psychiatry 1998;64:806-808)
\end{abstract}

Department of

Neurology,

Medizinische

Universität zu Lübeck,

Germany

M Nitschke

I Heberlein

V Otto

P Vieregge

Institute of Human Genetics, Justus von Liebig-Universität Gießen, Germany

D Steinberger

U Müller

Correspondence to: Dr P Vieregge, Department of Neurology, Medical University of Lübeck, Ratzeburger Allee 160, D-23538 Lübeck, Germany. Telephone 0049451500 2928; fax 0049451500 2489 .

Received 10 June 1997 and in revised form 15

September 1997

Accepted 19 November 1997
Keywords: dopa responsive dystonia; Turner's syndrome; GTP-cyclohydrolase I gene

Dopa responsive dystonia typically begins in early childhood with gait instability and equinovarus posturing of the feet. Signs and symptoms worsen during the day or after exercise, but are improved by levodopa. The disease may progress to generalised dystonia, whereas in other patients parkinsonian symptoms may develop. ${ }^{12}$ Intelligence and body growth are usually normal in dopa responsive dystonia. ${ }^{3}$ Apart from rare autosomal recessive transmission ${ }^{45}$ the disease is mostly inherited as an autosomal dominant trait with incomplete penetrance, and women are affected more often than men. ${ }^{2}$ Mutations in the gene of GTP-cyclohydrolase I (GCH I) mapping to chromosome 14q21-22 have been found to cause dopa responsive dystonia. Until now point mutations in various exons ${ }^{6-11}$ as well as exon skipping has been reported in the respective families. ${ }^{612}$ However, there are also reports of families with typical dopa responsive dystonia but without any mutation in this gene. ${ }^{8}{ }^{12}$ Here, we present the association of the disease with Turner's syndrome in an index patient whose five generation pedigree disclosed other relatives with dopa responsive dystonia. Another new mutation in the GCH I gene probably accounting for the disease in this family is presented. We also investigated quantitatively the neuropsychological abilities in three patients with dopa responsive dystonia before and after levodopa therapy.

\section{Case 1}

The index patient, now aged 28, had a normal birth. After delay of early motor milestones she began to walk at the age of two years, but was more clumsy than her companions. Since the age of 4 she had crural dystonia with equinovarus posturing and gait instability. During the subsequent years symptoms slowly progressed towards generalised dystonia that exacerbated during exercise and improved after rest or sleep. Treatment with trihexyphenidyl since the age of 4 (until presentation) somewhat improved her symptoms for a few hours. During outdoor activities the patient had to use a wheelchair. There was no intellectual handicap, and she went to school until the age of 14 when she was discharged to a school for the physically handicapped. She had not had any oestrogen treatment before the first presentation to our department in November 1993. At that time she presented with short, corpulent stature $(1.45 \mathrm{~m}, 65 \mathrm{~kg})$, short neck and limbs, multiple cutaneous naevi, and primary amenorrhoea. Speech was slurred. There was laterocollis, axial dystonia, dystonic postures of all four limbs with inversion, and equinovarus posturing of toes and feet. She was wheelchair bound and could not walk. The remainder of the neurological examination was normal. Laboratory investigation was normal including examination of CSF, iron and copper studies, lactate, liver function tests, and routine blood and urinary tests. Tests of endocrine function were consistent with a primary amenorrhoea: LH $(16.4 \mathrm{mU} / \mathrm{ml})$ and $\mathrm{FSH}(40.8 \mathrm{mU} / \mathrm{ml})$ were greatly increased; $\mathrm{TSH}, \mathrm{T} 3$, and $\mathrm{T} 4$ were normal as were ECG, EEG, and CCT. Brain MRI showed a decreased signal in the globus pallidus bilaterally (figure). Abdominal 


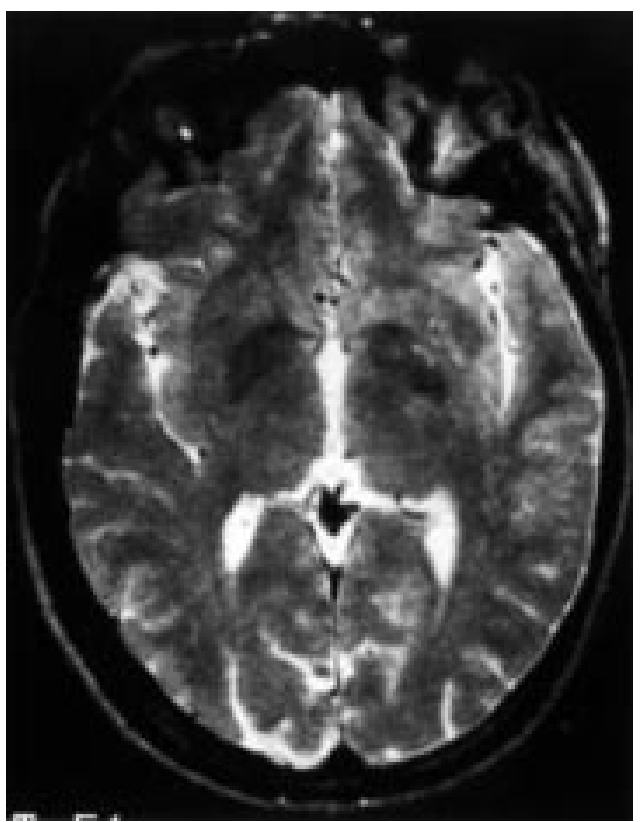

T2 weighted MRI of patient 1 showing considerable hypointensity of the globus pallidus bilaterally.

ultrasound disclosed incomplete horseshoe kidneys. The patient had a karyotype of 45,X indicating Turner's syndrome. Dystonia improved dramatically after a test dose of $200 \mathrm{mg}$ levodopa. With regular treatment with $250 \mathrm{mg}$ levodopa/day laterocollis, axial dystonia, and dystonic postures have disappeared. After motor learning during several months the patient is now able to stand and walk without any impairment.

\section{Case 2}

The patient's mother (now aged 56) had gait instability and dystonic leg cramps from early childhood. She reported symptom alleviation with menarche. She now has slight facial dystonia, dysarthria, torticollis, and dystonic postures of toes and feet during walking that nearly disappeared after institution of $125 \mathrm{mg}$ levodopa/day.

\section{Case 3}

The 43 year old maternal aunt of the index case (sister of case 2) developed gait instability due to trunk and neck dystonia, retrocollis, and dystonic posturing of her arms during childhood. Symptoms fluctuated during the day,

Table 1 Results of fine motor and neuropsychological testing in the three patients with dopa responsive dystonia

\begin{tabular}{|c|c|c|c|c|c|c|}
\hline \multirow[b]{2}{*}{ Levodopa } & \multicolumn{2}{|c|}{ Case 1} & \multicolumn{2}{|c|}{ Case 2} & \multicolumn{2}{|c|}{ Case 3} \\
\hline & - & + & - & + & - & + \\
\hline \multicolumn{7}{|l|}{ Hand tapping rate: } \\
\hline Right & 59 & 81 & 63 & 64 & 59 & 81 \\
\hline Left & 35 & 51 & 16 & 50 & 60 & 60 \\
\hline \multicolumn{7}{|l|}{ WAIS: } \\
\hline Total IQ & 81 & 91 & 94 & 101 & 83 & 92 \\
\hline Verbal IQ & 84 & 90 & 94 & 99 & 84 & 87 \\
\hline Performance IQ & 80 & 93 & 95 & 104 & 86 & 101 \\
\hline \multicolumn{7}{|l|}{ WCST: } \\
\hline Categories & 3 & 5 & 1 & 3 & 1 & 2 \\
\hline Errors $(20.9+/-11.6)$ & 26 & 13 & 33 & 21 & 39 & 29 \\
\hline Perseveration & 7 & 3 & 8 & 7 & 6 & 5 \\
\hline
\end{tabular}

Patients were tested once without levodopa substitution $(-)$ and once with levodopa substitution $(+)$. Reference values for the normal range are given in parentheses. ${ }^{16}$ worsening towards evening. Dystonia of the facial muscles, neck, shoulders, hands, and feet were much improved by levodopa $(375 \mathrm{mg} /$ day). Blepharospasm and retrocollis were successfully treated with additional local botulinum toxin $\mathrm{A}$ injections. In patients 2 and 3 laboratory investigation, including CSF, iron and copper studies, liver function tests, and routine blood, urinary, and karyotype analysis were unremarkable as were EEG and brain MRI. Neopterin studies in CSF of the three cases were not performed.

\section{Pedigree}

The patients were members of a pedigree comprising 101 probands, 35 of whom were investigated personally. No other case of Turner's syndrome was detected. A maternal grandfather (aged 89) of case 1 has had senile parkinsonism for 14 years, his niece (aged 68) isolated postural tremor for four years. The gene locus of the informative members of the family was assigned to chromosome 14q22.1q22.2. Single strand conformation polymorphism analysis $^{13}$ of exon 1 of the gene GTP-cyclohydrolase I (GCH I) disclosed a bandshift in all affected but not in unaffected family members. Subsequent sequence analysis showed a G-T transversion at position 181 of the genomic sequence. This results in a stop codon at amino acid position 61 and therefore a truncation of the polypeptide.

\section{Neuropsychology}

The table shows the results of hand tapping over 16 seconds $^{14}$ for each hand and of neuropsychological testing in the cases before and after at least seven days of institution of levodopa therapy. Hand tapping improved, although to a different degree, in all three cases for both hands under levodopa treatment. Similarly, IQ, measured with the German version of the Wechsler adult intelligence scale $\left(\right.$ WAIS $^{15}$ ), showed some improvement when tested under medication. This was largely attributable to improvements in the performance part of the WAIS, in which scorings in the mosaic test of three dimensional visual performance were higher. By contrast, verbal IQ did not change under levodopa treatment. Concept formation and set shifting abilities were assessed with Nelson's modified version of the Wisconsin card sorting test $\left(\mathrm{WCST}^{16}\right)$. Values were taken as raw scores; mean values of errors were compared with those of the patients with frontal lobe lesions in the study of Nelson. ${ }^{16}$ All three patients had fewer errors and perseverations and achieved more categories while under levodopa.

\section{Discussion}

Disease course, clinical presentation, response to levodopa substitution, and molecular genetic analysis point to a diagnosis of dopa responsive dystonia in all three cases. ${ }^{17}$ Delay of motor milestones as found in our index patient is ununsual but not unknown in dopa responsive dystonia. ${ }^{18}$ Our index patient has more severe disease affliction than her relatives with the desease in the parent generation. As she 
also has Turner's syndrome, this raises speculations about the effect of a sex chromosome abnormality on a disease with sex specific penetrance such as dopa responsive dystonia. In view of prevalence rates for dopa responsive dystonia ( 0.5 per million $\left.{ }^{19}\right)$ and for Turner's syndrome $\left(1\right.$ per $\left.8000^{19}\right)$ the association in our patient seems so unique that chance is the most likely explanation for its occurrence. The afflicted members of the family show a mutation within the GCH I gene resulting in truncation of the GCH I. Such truncation of the GCH I is often found in dopa responsive dystonia as a result of different mutations and reduces the total amount of active enzyme in the patients. Our mutation finding has not been described for any of the families with dopa responsive dystonia published so far. It underlines the finding that for this rare autosomal dominant disorder there is obviously no common mutation within the GCH I gene. ${ }^{8}$

The detection of a decreased signal in the globus pallidus on T2 images of brain MRI in the index patient contrasts with earlier reports in dopa responsive dystonia: Pallidal signals were either normal or even hyperintense. ${ }^{20} \mathrm{Pal}-$ lidal hypointensity is to a variant degree seen in dystonic conditions of different aetiologies. ${ }^{20}$ Information on brain MRI morphology in Turner's syndrome is restricted to area measurements under developmental aspects. ${ }^{21}{ }^{22}$ So, whether the globus pallidus abnormality is linked to the pathophysiology of Turner's syndrome rather than to that of dopa responsive dystonia is only speculative. This conclusion is somewhat supported by the fact that brain MRI studies in both the other relatives with dopa responsive dystonia were normal. Irrespective of aetiology; however, the MRI features of the index patient may be relevant for the judgement of motor performance: in healthy adults iron related signal loss on T2 weighted images in the globus pallidus has been found with poor performance on motor and specific cognitive tasks. ${ }^{23}$

By an instrumental hand tapping test objective motor improvement as an effect of levodopa treatment was shown in all three cases of dopa responsive dystonia. The improvement of IQ with levodopa treatment was largely attributable to the performances in the mosaic test. This test assesses three dimensional visual performance; our result may therefore point to improved spatial orientation in dopa responsive dystonia with levodopa therapy similar to the effects found in Parkinson's disease. ${ }^{24}$ In a similar way the patients with dopa responsive dystonia improved in their test performances in the WCST when tested under levodopa treatment. Clearly, IQ and WCST were each applied twice without balancing sequence and performance effects. Thus the improvements in performance of our small sample should be judged with caution. Until now there is no in depth assessment of neuropsychological function in adult patients with dopa responsive dystonia. Impaired performance could, however, be anticipated in various test domains in unmedicated or undermedicated patients with dopa responsive dysto- nia, as in Parkinson's disease. ${ }^{25}$ This would be attributable to a frontostriatal postsynaptic "low dopamine syndrome". This suggestion is derived from recent pathological data of severe dopamine reductions in caudate and putamen in dopa responsive dystonia similar to those measured in Parkinson's disease. ${ }^{26}$

We thank Dr G van Bentum for referring the index case, Professor H D Weiss, Department of Radiology, Medical University of Lübeck, for providing the MR images, Professor E Schwinger, Institute of Human Genetics, Medical University of Lübeck, for karyotype analysis, and Y Weber for technical assistance.

1 Nygaard TG, Marsden CD, Duvoisin RC. Dopa-responsive dystonia. Adv Neurol 1988;50:377-84.

2 Nygaard TG, Trugman JM, de Yebenes JG, et al. Dopa-responsive dystonia: the spectrum of clinical manifestations in a large North American family. Neurology 1990;40:66-9.

3 Harwood G, Hierons R, Fletcher NA, et al. Lessons from a remarkable family with dopa-responsive dystonia. $\mathcal{F}$ Neurol Neurosurg Psychiatry 1994;57:460-3.

4 Lüdecke B, Dworniczak B, Bartholomé K. A point mutation in the tyrosine hydroxylase gene associated with Segawa's syndrome. Hum Genet 1995;93:123-5.

5 Knappskog PM, Flatmark T, Mallet J, et al. Recessively inherited L-DOPA-responsive dystonia caused by a point mutation $(\mathrm{Q} 381 \mathrm{~K})$ in the tyrosine hydroxylase gene. Hum Mol Genet 1995;4:1209-12.

6 Ichinose H, Ohye T, Takahashi E-I, et al. Hereditary progressive dystonia with marked diurnal fluctuation caused by mutations in the GTP cyclohydrolase I gene. Nat Genet 1994;8:236-42.

7 Ichinose H, Ohye T, Segawa M, et al. GTP cyclohydrolase I gene in hereditary progressive dystonia with marked diurnal fluctuation. Neurosci Lett 1995;196:5-8

8 Bandmann O, Nygaard T, Surtees R, et al. Dopa-responsive dystonia in British patients: new mutations of the GTP cyclohydrolase I gene and evidence for genetic heterogeneity. Hum Mol Genet 1996;5:403-6.

9 Furukawa Y, Shimadzu M, Rajput AH, et al. GTP cyclohydrolase I gene mutations in hereditary progressive and dopa-responsive dystonia. Ann Neurol 1996;39:609-17.

10 Hirano M, Tamaru Y, Ito H, et al. Mutant GTP cyclohydrolase I mRNA levels contribute to dopa-responsive dystonia onset. Ann Neurol 1996;40:796-8.

11 Brique S, Chartier-Harlin MC, Dhondt JL, et al. A new mutation of GTP cyclohydrolase I gene causative for doparesponsive dystonia in a French family. Mov Disord 1997;12 (suppl II):67.

12 Hirano M, Tamaru Y, Nagai Y, et al. Exon skipping caused by a base substitution at a splice site in the GTP cyclohydrolase I gene in a Japanese family with hereditary cyclohydrolase 1 gene in a Japanese family with hereditary progressive dystonia/dopa responsive
Biophys Res Commun 1995;213:645-51.

13 Steinberger D, Müller U. Molekulargenetik und Klinik der Dopa-responsiven Dystonie. Dt Ärztebl 1996; 93:B1271-3.

14 Schoppe KJ. Das MLS-Gerät: Ein neuer Testapparat zur Messung feinmotorischer Leistungen. Diagnostica 1980;20: 43-6.

15 Wechsler D. Handanweisung zum Hamburg-WechslerIntelligenztest für Erwachsene (HAWIE). Bern: Hans Huber, 1982 .

16 Nelson HEA. A modified card sorting test sensitive to frontal lobe defects. Cortex 1976;12:313-24.

17 Nygaard TG. Dopa-responsive dystonia. Curr Opin Neurol 1995;8:310-3.

18 Nygaard TG, Waran SP, Levine RA, et al. Dopa-responsive dystonia simulating cerebral palsy. Pediatr Neurol 1994;11: 236-40.

19 Leiber B, Olbrich G. Die klinischen Syndrome. Band 1, 6 . Auflage. München: Urban und Schwarzenberg, 1981.

20 Iwata M. MRI pathology of basal ganglia in dystonic disorders. Adv Neurol 1993;60:535-9.

21 Ross JL, Reiss AL, Freund L, et al. Neurocognitive function and brain imaging in Turner syndrome-Preliminary results. Horm Res 1993;39(suppl 2):65-9.

22 Murphy DGM, DeCarli C, Daly E, et al. X-chromosome effects on female brain: a magnetic resonance imaging study of Turner's syndrome. Lancet 1993;342:1197-200.

23 Pujol J, Junque C, Vendrell P, et al. Biological significance of iron-related magnetic resonance imaging changes in the brain. Arch Neurol 1992;49:711-7.

24 Loranger AW, Goodell H, Lee JE, et al. Levodopa treatment of Parkinson's syndrome. Arch Gen Psychiatry 1972;26: 163-8.

25 Cooper JA, Sagar HJ, Jordan N, et al. Cognitive impairment in early, untreated Parkinson's disease and its relationship to motor disability. Brain 1991; 114:2095-122.

26 Rajput AH, Gibb WRG, Zhong XH, et al. Dopa-responsive dystonia: pathological and biochemical observations in a case. Ann Neurol 1994;35:396-402. 